\title{
Experimental Investigation on Friction Welding of UNS S32205 Duplex Stainless Steel
}

\author{
P. M. Ajith $\cdot$ P. Sathiya $\cdot$ S. Aravindan
}

Received: 22 October 2013/Revised: 29 March 2014/Published online: 26 July 2014

(C) The Chinese Society for Metals and Springer-Verlag Berlin Heidelberg 2014

\begin{abstract}
UNS S 32205 duplex stainless steel specimens were joined by continuous drive friction welding process. The experiments were conducted as per the Taguchi (L16 orthogonal array) method. The friction welding process parameters such as heating pressure, heating time, upsetting pressure, upsetting time, and speed of rotation were fixed with low, medium, and high levels of range based on the machine capacity, and the required knowledge was acquired from the preliminary experiments. The joint characterization studies included micro structural examination and evaluation of mechanical properties of the joints. Microhardness variation, impact toughness, and tensile strength of the joints were evaluated. Neither a crack nor an incomplete bonding zone was observed. The tensile strength of the joints was higher than the strength of the base material, and the friction and upsetting pressures were found to influence the joint strength. The tensile strength of all the welds was observed to be increasing with an increase in the rotational speed. The toughness of the friction welds was evaluated at room temperature and also at subzero (cryo) temperature conditions. The toughness for friction welds was found to be superior to the fusion welds of duplex stainless steel at room temperature and cryo conditions. Weldments exhibited better corrosion resistance than the parent material.
\end{abstract}

KEY WORDS: Duplex stainless steel; Hardness; Tensile strength; Toughness; Microstructure; Corrosion

\section{Introduction}

Duplex stainless steel (DSS) is well known for its higher mechanical strength and better corrosion resistance. DSS is commonly used in marine, petrochemical, and chemical industries. DSS 2205 has an equal amount of $\alpha$ and $\gamma$

Available online at http://link.springer.com/journal/40195

P. M. Ajith · P. Sathiya ( $₫)$

Department of Production Engineering, National Institute of

Technology, Tiruchirappalli 620015, Tamilnadu, India

e-mail: psathiya@nitt.edu

S. Aravindan

Department of Mechanical Engineering, Indian Institute of

Technology Delhi, New Delhi 110016, India phases. DSS offers an alternative to the austenitic stainless steels especially at temperatures between -50 and $300{ }^{\circ} \mathrm{C}$ and is also suitable for structural applications. The twophase structure of ferrite and austenite combines the beneficial effects of the phases and allows the steel to obtain high strength (ferrite) and toughness (austenite) even at low temperatures. The high strength makes it possible to use thinner dimensions and accomplish weight savings. Furthermore, the material offers good resistance to localized corrosion due to high $\mathrm{Cr}$, Mo, and $\mathrm{N}$ additions, and stress corrosion cracking due to the ferrite content [1]. Other advantages of DSS are its satisfactory fatigue properties [2, 3], modest thermal expansion and low nickel content, and its modest cost [1]. The phase balance in DSS obtained by careful heat treatment is crucial for the mechanical properties. When duplex stainless steels are annealed at a temperature range of $1,000-1,150{ }^{\circ} \mathrm{C}$, only $\alpha$ and $\gamma$ phases could be seen. Generally, the rapid cooling is needed to 
prevent the formation of other phases. Duplex stainless steels are not stable below $1,000{ }^{\circ} \mathrm{C}$ because of the formation of various carbides, brittle chrome phases ( $\sigma$ and $\lambda$ ), and primary alpha $(\alpha)$ [4-6]. DSS solidifies ferritically at a moderate cooling rate during welding, and the production process promotes a favorable phase proportion. Long holding time at temperatures between 300 and $1,000{ }^{\circ} \mathrm{C}$ and very slow cooling rate are not recommended in order to avoid precipitation of brittle intermetallic phases, such as $\sigma$ and $\chi[7-13]$. The ferritic solidification promotes resistance to solidification cracking [14]. DSS exhibits good weldability due to its low nickel content. But the melting and solidification associated with fusion welding process not only destroy the favorable duplex microstructure of these stainless steels but also lead to detrimental intermetallic phases. Higher ferrite content and coarse grains are other factors which decrease both the corrosion resistance and the mechanical properties of welded joints [15]. Cvijović et al. [16] have studied the solidification in welds of a duplex stainless steel with $(\mathrm{Cr} / \mathrm{Ni})_{\mathrm{eq}}=1.8$ at various cooling rates. For cooling rates varying from 10 to $10^{3} \mathrm{~K} / \mathrm{s}$ and low under cooling $(1.5-1.3 \mathrm{~K})$, it has been concluded that the microstructural morphology changed from thick to thin intercellular $\gamma$ with the increased volume fraction of ferrite $\delta$.

The parts having same and different diameters of plastically deformed steel bars were welded with different friction welding parameters. The hardness variation in the horizontal direction of the joints was reported to be increasing at the central zone due to rapid cooling [17].

However, there are very limited studies on friction welding of UNS S32205 duplex stainless steel. In the case of friction welding, heating pressure and upsetting pressure are the most important parameters among others such as heating time, upsetting time, and speed of rotation. It is also noted that there is only very limited reports available on the mechanical and metallurgical properties of UNS S 32205 friction welds. In the present study, specimens were joined by L 16 orthogonal array with different friction welding parameters such as heating pressure (HP), heating time (HT), upsetting pressure (UP), upsetting time (UT), and speed of rotation (SoR). The joint is characterized through microstructural examination, and evaluation of the mechanical properties of the joints such as impact toughness and tensile strength was carried out. Pitting corrosion behavior of the welds was also studied.

\section{Experimental}

The steel used in this investigation was UNS S32205 of a commercial grade, received in the form of rod with a diameter of $15 \mathrm{~mm}$. Its chemical composition is given in Table 1. The experiments were conducted as per the L16 orthogonal array matrix. The input parameters were heating pressure (HP), heating time (HT), upsetting pressure (UP), upsetting time (UT), and speed of rotation (SoR), and four levels were fixed and the parameters and their levels are presented in Table 2. The test specimens were obtained from the cross section of the joint area.

The specimens were mounted and later flatted and then polished using $\mathrm{SiC}$ abrasive paper with grit ranges from 180 to 1,200 . Then the samples were lightly polished using $3 \mu \mathrm{m}$ diamond paste. Samples were then washed, cleaned by acetone, and then dried, followed by electrolytic etching in $10 \%$ oxalic acid at $9 \mathrm{~V}$ for $30 \mathrm{~s}$ as per ASTM: E3-11. Microstructural examinations were carried out at various cross sections of the weld using optical microscope. Ferrite percentages were measured using ferrite scope, and also the percentage of ferrite was calculated using $\mathrm{Cr}$ eq and $\mathrm{Ni}$ eq. In order to detect various phases present in the weldment, X-ray diffraction (XRD) studies were carried out on all welds. X-ray diffraction was carried out on planar surfaces of these weld fusion zones. Rigaku Ultimate 3 (Japan) $\mathrm{X}$-ray diffractometer with $\mathrm{Cu} K_{\alpha}$ radiation of wavelength $0.1544 \mathrm{~nm}$ was used. The phases were analyzed with optical microscopy and JEOL JSM-5610 LV scanning electron microscope (SEM). The specimens for Charpy test were taken as perpendicular to weld direction according to the ASTM: E23 standards. The specimens for tensile test were prepared in accordance with the relevant ASTM E 8, and tests were carried out using 40 ton universal testing machine at room temperature. The impact tests were conducted at room temperature, $-50,-100,-150$, and $-196{ }^{\circ} \mathrm{C}$. Microhardness measurements were taken at parent metal, partially deformed zone (PDZ), and weld zone with a load of $4.9 \mathrm{~N}$ for $10 \mathrm{~s}$ during measurements. The fractured surfaces were studied through scanning electron microscope (SEM) equipped with energy dispersive spectrometer (EDS) to study the quantitative analysis of the welds. The corrosion tests were conducted at room temperature using Electrochemical Analyzer. The tests were conducted in a conventional three-electrode cell, with Pt foil as the auxiliary electrode, and a saturated electrode (SCE) as the reference electrode. The working electrode

Table 1 Base material chemical composition (wt \%)

\begin{tabular}{llllllllll}
\hline $\mathrm{C}$ & $\mathrm{Si}$ & $\mathrm{Mn}$ & $\mathrm{P}$ & $\mathrm{S}$ & $\mathrm{Cr}$ & $\mathrm{Mo}$ & $\mathrm{Ni}$ & $\mathrm{N}$ & $\mathrm{Fe}$ \\
\hline 0.021 & 0.357 & 1.61 & 0.026 & 0.001 & 22.50 & 3.38 & 4.79 & 0.193 & $\mathrm{Rest}$ \\
\hline
\end{tabular}



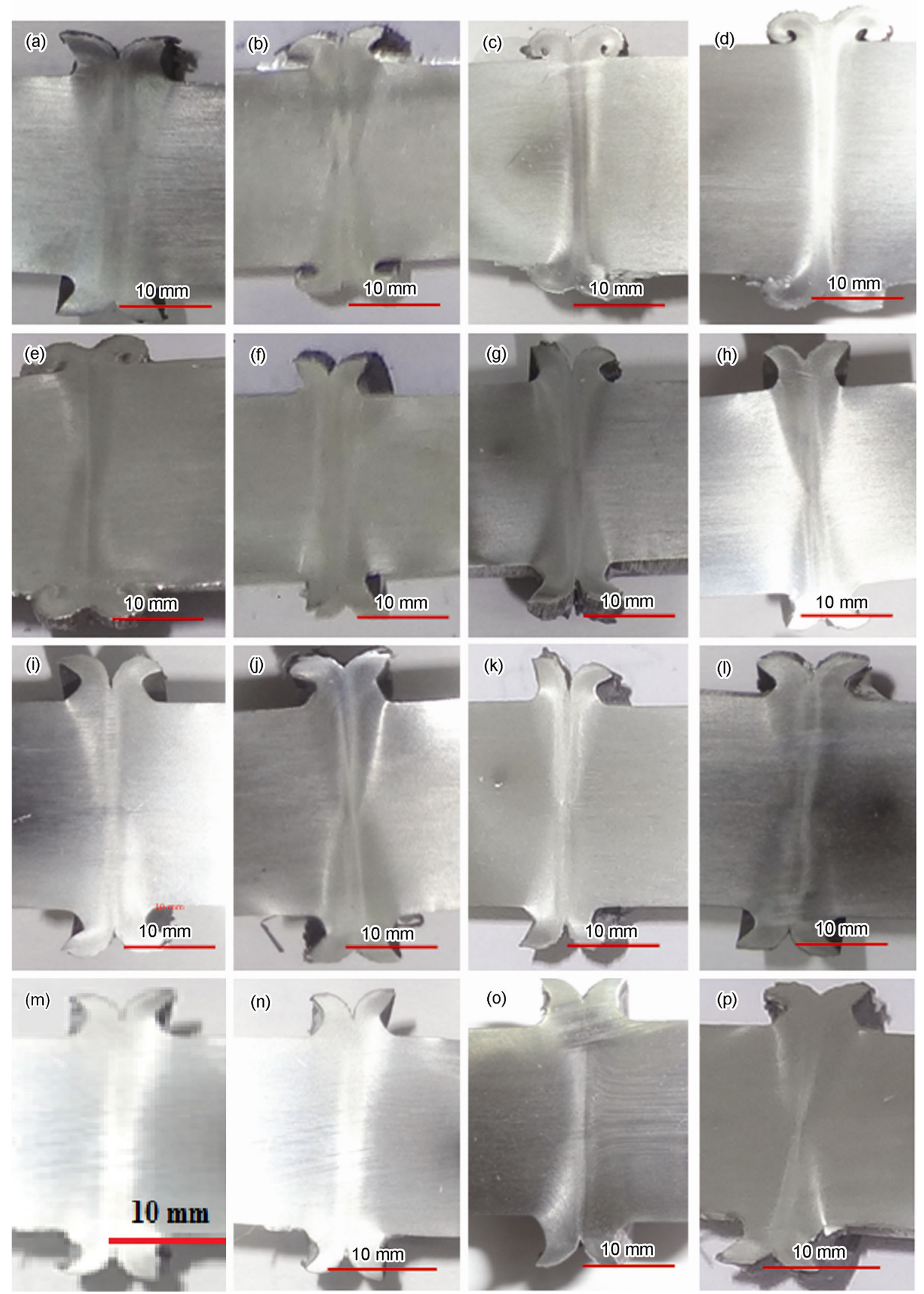

Fig. 1 Macrographs of the friction weld joints: a Exp. No. 1, b Exp. No. 2, c Exp. No. 3, d Exp. No. 4, e Exp. No. 5, f Exp. No. 6, g Exp. No. 7 , h Exp. No. 8, i Exp. No. 9, j Exp. No. 10, k Exp. No. 11, l Exp. No. 12, m Exp. No. 13, n Exp. No. 14, o Exp. No. 15 , p Exp. No. 16 
Table 2 List of friction welding parameters used in the preparation of weldment

\begin{tabular}{llllll}
\hline Exp. No. & HP $(\mathrm{MPa})$ & UP $(\mathrm{MPa})$ & HT (s) & UT (s) & SoR (r/min) \\
\hline 1 & 70 & 145 & 6 & 3 & 1,500 \\
2 & 70 & 155 & 7 & 4 & 2,000 \\
3 & 70 & 165 & 8 & 5 & 2,500 \\
4 & 70 & 175 & 9 & 6 & 3,000 \\
5 & 80 & 145 & 7 & 5 & 3,000 \\
6 & 80 & 155 & 6 & 6 & 2,500 \\
7 & 80 & 165 & 9 & 3 & 2,000 \\
8 & 80 & 175 & 8 & 4 & 1,500 \\
9 & 90 & 145 & 8 & 6 & 2,000 \\
10 & 90 & 155 & 9 & 5 & 1,500 \\
11 & 90 & 165 & 6 & 4 & 3,000 \\
12 & 90 & 175 & 7 & 3 & 2,500 \\
13 & 100 & 145 & 9 & 4 & 2,500 \\
14 & 100 & 155 & 8 & 3 & 3,000 \\
15 & 100 & 165 & 7 & 6 & 1,500 \\
16 & 100 & 175 & 6 & 5 & 2,000 \\
\hline
\end{tabular}

was constructed using DSS samples embedded in epoxy resin, with a copper wire providing electrical contact. The working solution was $3.5 \% \mathrm{NaCl}$ solution.

\section{Results and Discussion}

\subsection{Macrograph of the Welded Joints}

The macrographs of the welds are presented in Fig. 1, and it revealed no defects in the joint zone. From Fig. 1, it is found that all the welds possessed symmetrically shaped uniform flash thickness. It was confirmed that both the adjacent sides of metals got equally softened.

\subsection{Influence of Chemical Composition on Phase Fractions (Austenite + Ferrite) of the Weld}

There are certain issues related to the influence of chemical composition on phase fractions (austenite + ferrite) of the weld. In general, the steel has higher amount of volume fraction of ferrite content than the austenite volume content in the weld. This affects the low-temperature notch toughness and corrosion resistance in the weld [18, 19]. During the welding of DSS, the austenite to ferrite ratio may change along with the precipitation of the intermetallic compounds. The phase ratio $(\gamma / \alpha)$ either in the fusion zone or in the heat-affected zone (HAZ) of a weld tends to deviate from the almost 1:1 ratio of the parent material. The chemical composition in each phase can also vary. The phase and the changes in the microstructural and chemical composition of the DSS welds may also depend on the peak temperature, heat input, preheat temperature, interpass temperature, and cooling rates of the weld/HAZ. These changes resulting from welding is detrimental as far as the corrosion resistance and mechanical properties are concerned [20-22]. The weld metal composition and the weld temperatures are to be carefully controlled during the welding operation to alleviate the above mentioned issues. Typical micrograph of the friction weld is presented in Fig. 2. The percentage of ferrite and austenite phases were mapped with image analyzing software, and ferrite number was measured using Fischer Feritscope MP 30, and their average values are presented in Table 3 .

From Table 3, it is observed that the ferrite phase percentage was higher than the austenite phase percentage for all the weld metals; however, the ferrite phase had a lower value in PDZ. The chemical composition of the weld metals was analyzed by EDS and it is listed in Table 4. The $\mathrm{Cr}_{\mathrm{eq}} / \mathrm{Ni}_{\mathrm{eq}}$ ratio calculated from the following equations [23] was $1.71-1.88$ for weld metal.

$$
\begin{aligned}
\mathrm{Cr}_{\text {eq }}= & \% \mathrm{Cr}+(1.5) \% \mathrm{Si}+1.4 \% \mathrm{Mo}+\% \mathrm{Nb}-4.99, \\
\mathrm{Ni}_{\text {eq }}= & \% \mathrm{Ni}+30 \% \mathrm{C}+(0.5) \% \mathrm{Mn}+26(\% \mathrm{~N}-0.02) \\
& +2.77
\end{aligned}
$$

A modified Schaeffler diagram indicates the relation between $\mathrm{Cr}$ and $\mathrm{Ni}$ equivalents and the phases present in the microstructure [24]. It has been reported [25] that when the ratio of $\mathrm{Cr}_{\mathrm{eq}} / \mathrm{Ni}_{\mathrm{eq}}$ is lower than 1.35 , solidification results in austenitic formation, and when it is greater than

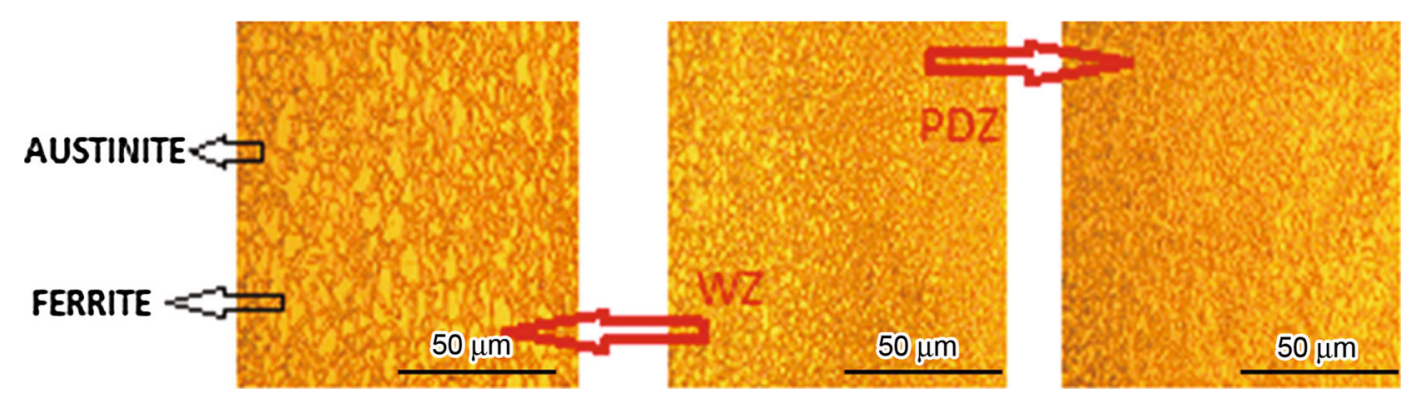

Fig. 2 Typical micrograph of the joint 
Table 3 Measured and predicted ferrite number friction weld zones

\begin{tabular}{lllll}
\hline Exp. No. & \multicolumn{2}{l}{ Ferrite number } & $\begin{array}{l}\text { Predicted ferrite } \\
\text { number in the } \\
\text { weld metal }\end{array}$ \\
\cline { 2 - 4 } & WM & PDZ & Base metal & 48 \\
\hline 1 & 53.34 & 47.18 & 51.98 & 46 \\
2 & 54.5 & 46.52 & 50.04 & 47 \\
3 & 51.88 & 45.14 & 48.26 & 46 \\
4 & 53.62 & 45.28 & 43.66 & 45 \\
5 & 55.76 & 45.32 & 47.78 & 48 \\
6 & 52.9 & 46.8 & 50.7 & 47 \\
7 & 52.3 & 43.8 & 48.1 & 46 \\
8 & 55.02 & 44.5 & 44.78 & 46 \\
9 & 51.86 & 44.46 & 47.7 & 47 \\
10 & 55.96 & 44.3 & 47.62 & 45 \\
11 & 52.1 & 46.6 & 49.1 & 46 \\
12 & 52.0 & 45.38 & 46.34 & 46 \\
13 & 52.78 & 41.28 & 44.16 & 45 \\
14 & 55.0 & 45.06 & 45.1 & 47 \\
15 & 54.68 & 45.68 & 48.46 & 46 \\
16 & 53.46 & 46.24 & 45.8 &
\end{tabular}

1.35 , ferrite is formed. From Table 4, it is clearly understood that the $\mathrm{Cr}_{\mathrm{eq}} / \mathrm{Ni}_{\mathrm{eq}}$ ratio was in between 1.71 and 1.88 for all the weld metal. Based on the chemical composition of the weld, the chromium equivalent and nickel equivalent were calculated, and ferrite percentages were predicted from the modified Schaeffler diagram. The predicted weld metal ferrite percentages are presented in Table 4.
Based on the ferrite percentage, it could be clearly indicated that the percentage of ferrite was much higher in weld zone compared to PDZ. The welds metal contained the ferrite and austenite phases in the form of matrix islands. In the weld metal, the austenite phase presented PDZ in the form of island and also had more grain boundaries than base metal. The elongation of grains appeared in the rotating direction.

\subsection{Microstructure of the Partially Deformed Zone (PDZ) and the Weld Metal (WM)}

Microstructural evaluation of friction-welded joints revealed four distinct zones in transverse direction to the bond line, as shown in Fig. 3. Those regions are named as weld zone (WZ), partially deformed zone (PDZ), and parent material (PM). The weld zone (WZ) and partial deformation zone (PDZ) microstructures are presented in Fig. 4.

Figure 4 clearly differentiates the size of the grains in the PDZ and the weld zone. And it also revealed that no internal defects were observed in all the partially deformed zone and weld metal in the microstructures. Based on the microstructural bonding, it was confirmed that the good metallurgical bonds were made in the joint area. The partly deformed zone (PDZ) had finer grain size than the weld zone grain size. The weld zone microstructure consisted of approximately equal volumes of ferrite and austenite phases. The weld zone microstructures consisted of large ferrite grains compared with PDZ microstructure and its continuous networks of austenite at the ferrite grain

Table 4 Chemical composition (wt\%) of weld metal and $\mathrm{Cr}_{\mathrm{eq}} / \mathrm{Ni}_{\mathrm{eq}}$ ratios

\begin{tabular}{lllllllllll}
\hline Exp. No. & $\mathrm{Cr}$ & $\mathrm{Mo}$ & $\mathrm{Si}$ & $\mathrm{Ni}$ & $\mathrm{C}$ & $\mathrm{N}$ & $\mathrm{Mn}$ & $\mathrm{Cr}_{\text {eq }}$ & $\mathrm{Ni}_{\text {eq }}$ & $\mathrm{Cr}_{\text {eq }} / \mathrm{Ni}_{\text {eq }}$ \\
\hline 1 & 22.60 & 3.31 & 0.38 & 5.02 & 0.012 & 0.142 & 1.54 & 22.814 & 12.092 & 1.88 \\
2 & 22.91 & 3.42 & 0.37 & 4.98 & 0.023 & 0.173 & 1.63 & 23.263 & 13.233 & 1.76 \\
3 & 22.16 & 3.27 & 0.42 & 5.12 & 0.019 & 0.145 & 1.73 & 22.378 & 12.575 & 1.78 \\
4 & 22.38 & 3.41 & 0.48 & 4.83 & 0.024 & 0.153 & 1.69 & 22.884 & 12.623 & 1.81 \\
5 & 22.54 & 3.29 & 0.39 & 5.10 & 0.018 & 0.162 & 1.85 & 22.741 & 13.027 & 1.74 \\
6 & 22.61 & 3.17 & 0.41 & 5.09 & 0.021 & 0.155 & 1.73 & 22.673 & 12.865 & 1.76 \\
7 & 22.76 & 3.28 & 0.44 & 4.89 & 0.025 & 0.149 & 1.51 & 23.022 & 12.519 & 1.84 \\
8 & 22.09 & 3.46 & 0.47 & 5.01 & 0.027 & 0.163 & 1.49 & 22.649 & 13.053 \\
9 & 22.81 & 3.39 & 0.39 & 5.07 & 0.019 & 0.168 & 1.53 & 23.151 & 13.023 & 1.73 \\
10 & 22.85 & 3.26 & 0.31 & 4.92 & 0.025 & 0.149 & 1.60 & 22.889 & 12.594 & 1.82 \\
11 & 22.91 & 3.20 & 0.43 & 4.87 & 0.023 & 0.171 & 1.67 & 23.045 & 13.091 & 1.76 \\
12 & 22.11 & 3.38 & 0.44 & 5.05 & 0.028 & 0.153 & 1.59 & 22.512 & 12.913 & 1.74 \\
13 & 22.73 & 3.39 & 0.47 & 5.11 & 0.022 & 0.156 & 1.43 & 23.191 & 12.791 & 1.81 \\
14 & 22.39 & 3.18 & 0.34 & 4.92 & 0.019 & 0.171 & 1.72 & 22.362 & 13.046 & 1.71 \\
15 & 22.43 & 3.40 & 0.36 & 4.79 & 0.024 & 0.162 & 1.63 & 22.74 & 12.787 & 1.78 \\
16 & 22.75 & 3.29 & 0.41 & 4.86 & 0.021 & 0.166 & 1.58 & 22.72 & 12.78 & 1.77 \\
Base metal & 22.43 & 3.38 & 0.35 & 4.77 & 0.025 & 0.193 & 1.61 & 22.69 & 13.59 & 1.66 \\
\hline
\end{tabular}




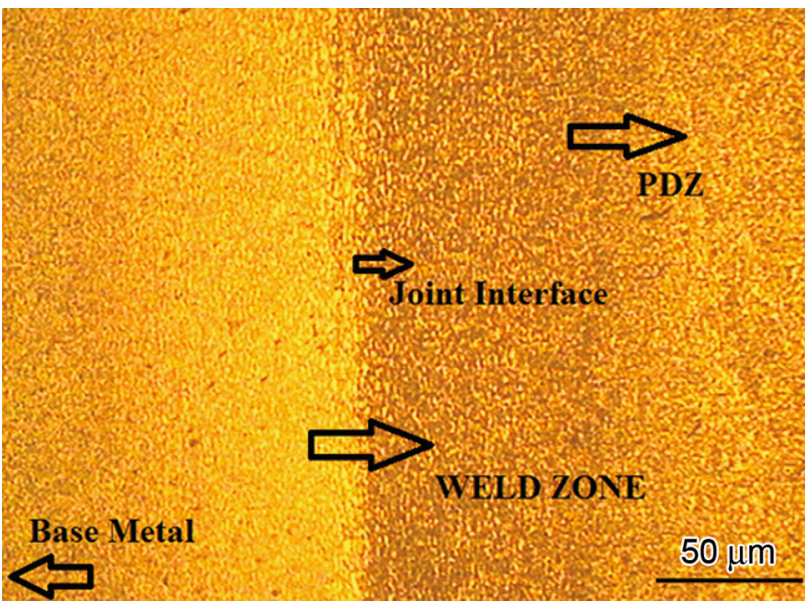

Fig. 3 Different zones at friction joint microstructure boundaries. Figure 4 reveals no intragranular austenite precipitates. Partially deformed zone microstructures had finer grain size than that weld microstructure. Figure $4 \mathrm{e}$ and $\mathrm{i}$ shows that the grains were elongated towards the weld center line due to rotating direction externally. This was due to the high amount of heating pressure and upsetting pressure. The observed coarse grains in Fig. 4b were attributed to the prevailing low heating pressure (70 MPa).

The weld zone was further investigated for phase identification and typical diffraction pattern by X-ray diffraction (Fig. 5). The main peaks in all these patterns correspond to the austenite $(\gamma)$ and ferrite $(\alpha)$ phases. No other carbides or oxides and intermetallic phases were revealed by X-ray diffraction patterns.
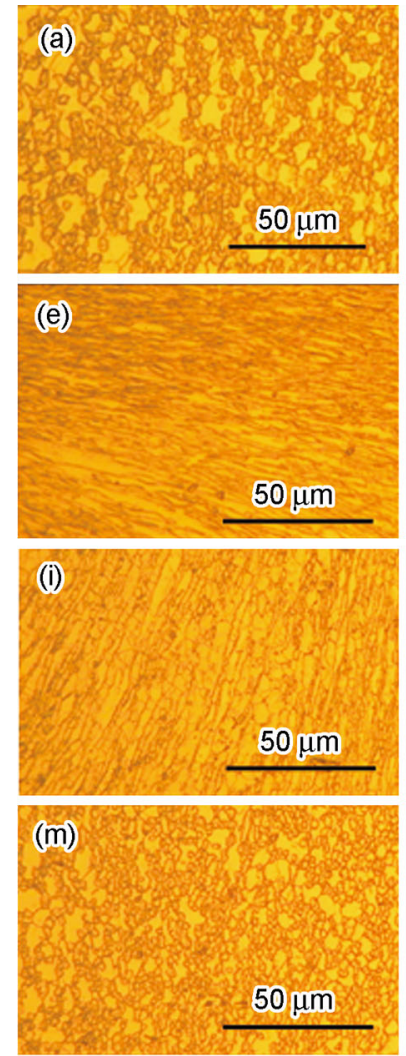
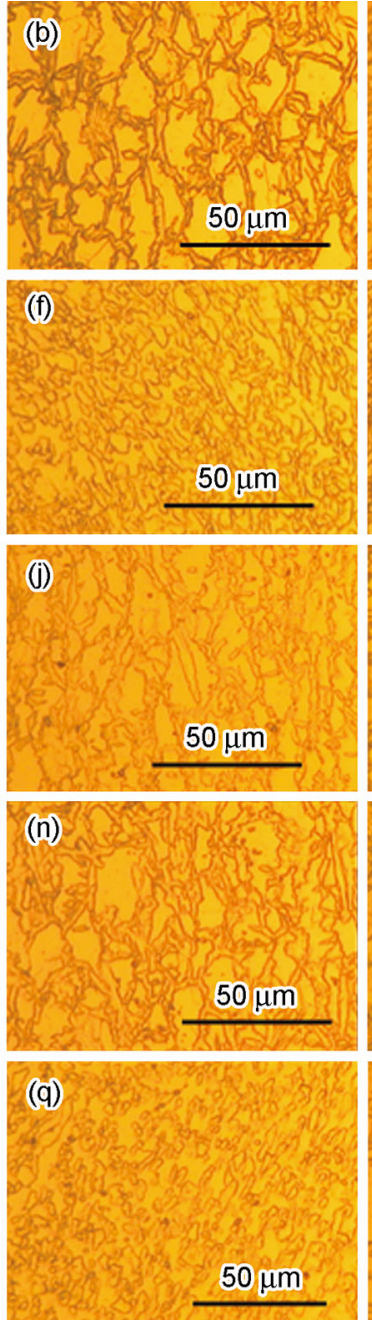
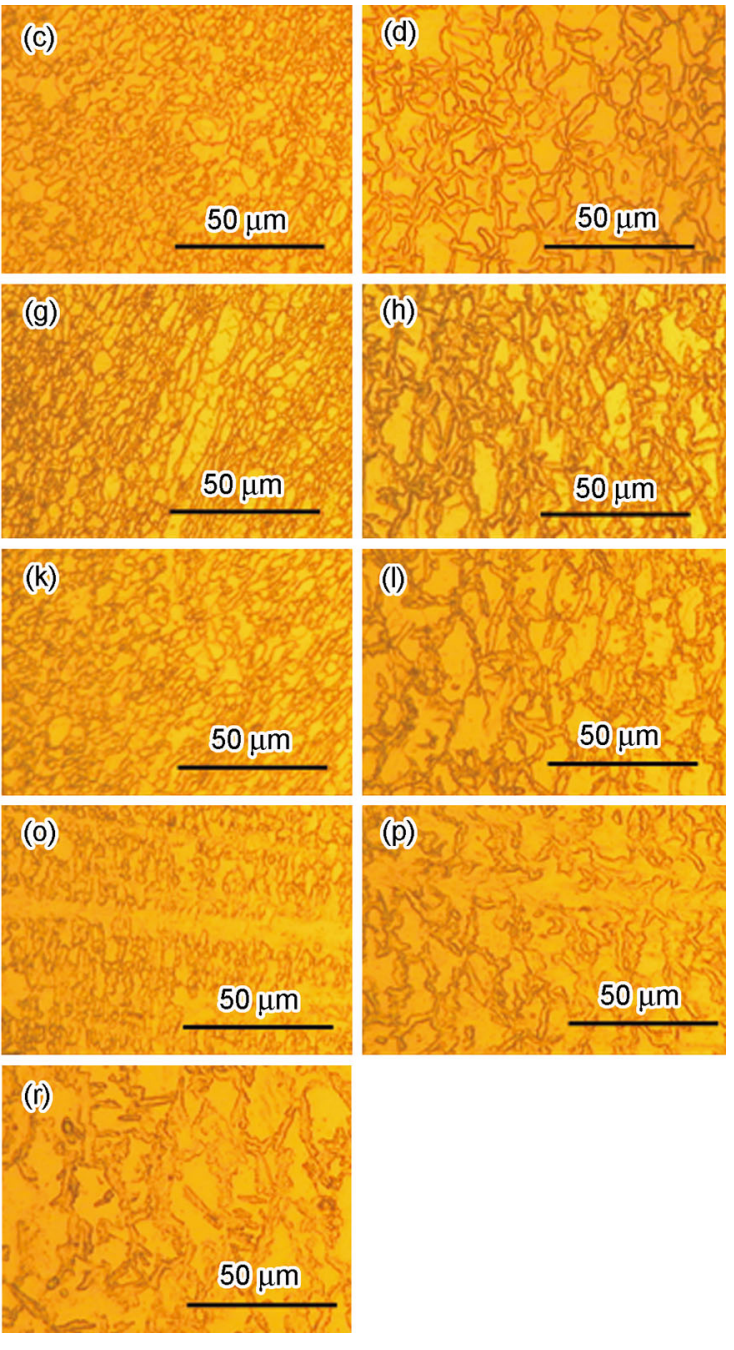

Fig. 4 PDZ and weld zone microstructures: a Exp. No. 1 PDZ, b Exp. No. 1 WM, c Exp. No. 2 PDZ, d Exp. No. 2 WM, e Exp. No. 5 PDZ, f Exp. No. 5 WM, g Exp. No. 7 PDZ, h Exp. No. 7 WM, i Exp. No. 10 PDZ, j Exp. No. 10 WM, k Exp. No. 12 PDZ, 1 Exp. No. 12 WM, m Exp. No. 13PDZ, n Exp. No. 13 WM, o Exp. No. 14 PDZ, p Exp. No. 14 WM, q Exp. No. 16 PDZ, r Exp. No. 16 WM 


\subsection{Microhardness of the Weld}

The typical microhardness profile is presented in Fig. 6. Three measurements were taken for every zone and graph was plotted. There was a variation in hardness values for the different regions like WZ, PDZ, and base metal. The grain sizes were also measured as per the ASTM standards in every zone, and their values are presented in Table 5.

In all welds, the highest hardness values were obtained in the PDZ, when compared to the weld zone. The variation of hardness values along the bond line showed an increasing trend, when moved from center to periphery. This was because of the existence of the coarse grains in the weld zone as one moved from center to the outer periphery towards PDZ and base metal. Weld zone hardness was higher than the base metal hardness, because of higher amount of ferrite phase. On the other hand, the strength had increased with increased volume fraction of ferrite phase. The weld zone had the equiaxed grains. The equiaxed grains were more pronounced in the austenite phase. This showed that the ferrite phase had a higher
Table 5 Measured grain size values $(\mu \mathrm{m})$

\begin{tabular}{llcclc}
\hline Exp. No. & WM & PDZ & Exp. No. & WM & PDZ \\
\hline 1 & 29.8 & 10.04 & 9 & 18.4 & 9.0 \\
2 & 27.5 & 16.01 & 10 & 19.1 & 8.27 \\
3 & 26.2 & 10.4 & 11 & 25.92 & 9.48 \\
4 & 20.97 & 12.8 & 12 & 25.25 & 9.53 \\
5 & 14.2 & 11.0 & 13 & 23.3 & 9.07 \\
6 & 12.8 & 11.4 & 14 & 25.3 & 9.45 \\
7 & 24.7 & 9.95 & 15 & 20.54 & 11.27 \\
8 & 14.2 & 7.85 & 16 & 21.45 & 10.21 \\
Average & 21.85 & 10.35 & & & \\
\hline
\end{tabular}

diffusion rate than the austenite phase, which produced a recrystallization and grain growth. There was no possibility for the formation of the intermetallic deleterious phases like sigma and chi phases. But these intermetallic phases were obtained by the other arc welding processes. The above mentioned phases were suppressed due to the faster cooling of the weld zone. Faster nucleation and growth
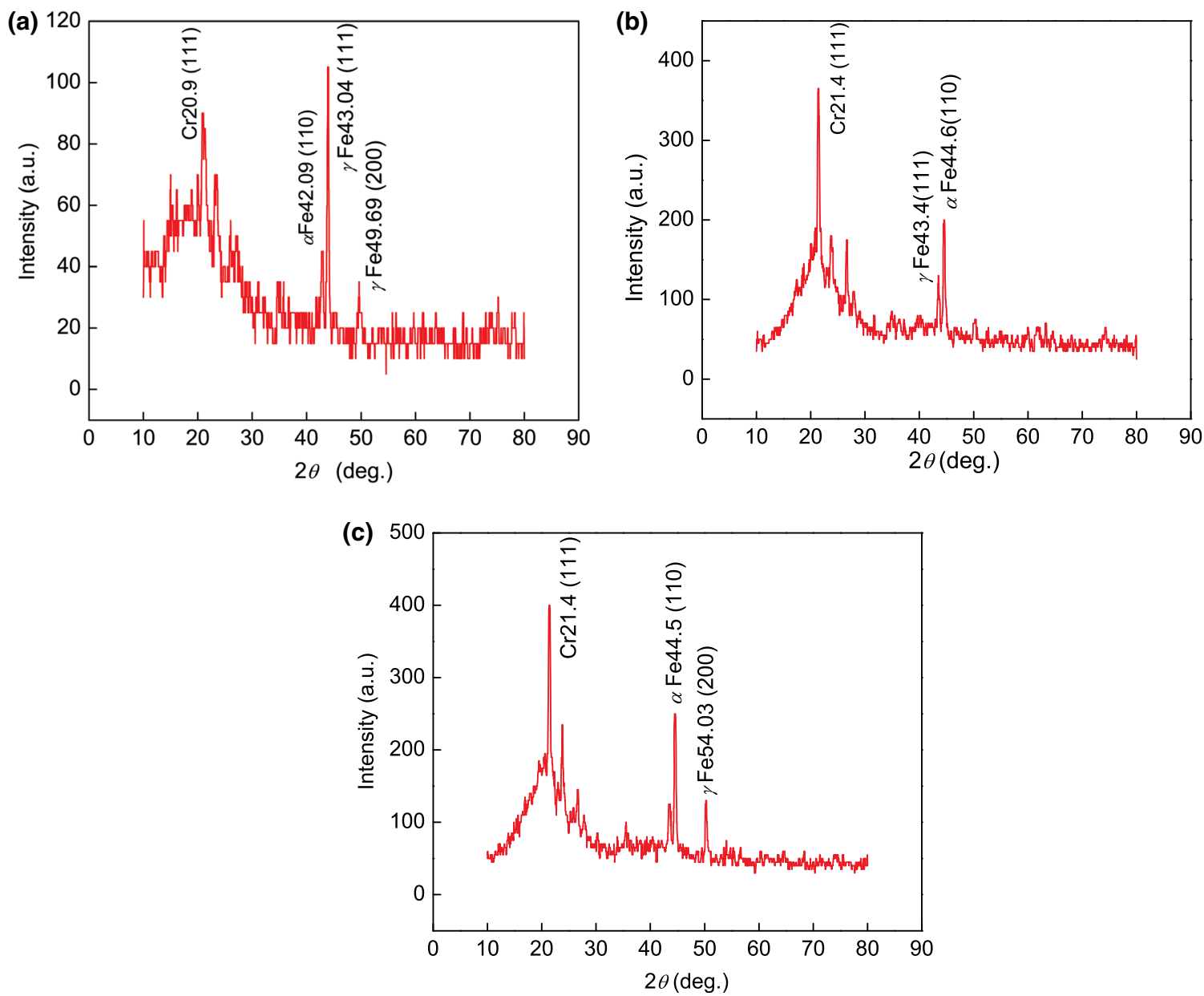

Fig. 5 X-ray diffraction patterns of friction welds: a Exp. No. 8, b Exp. No. 9, c Exp. No. 13 


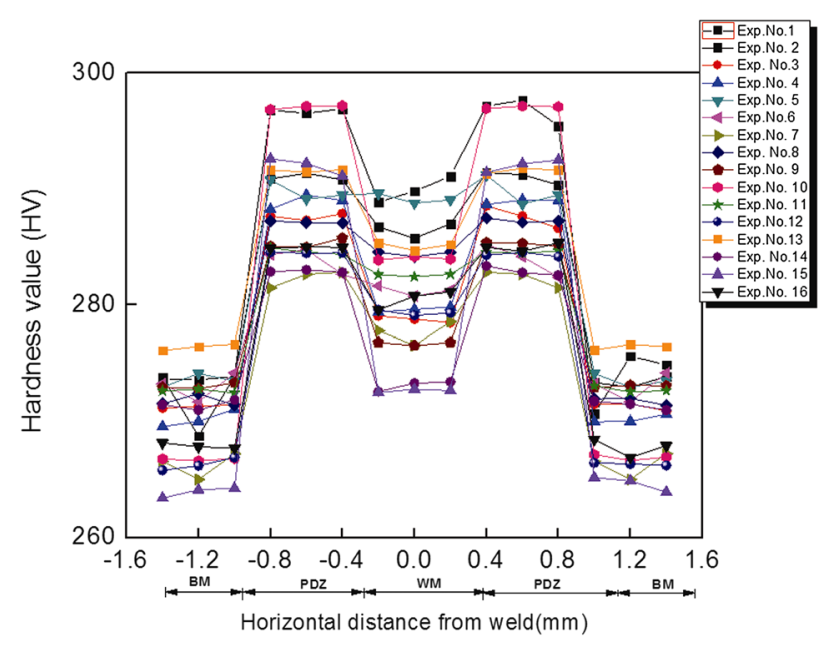

Fig. 6 Microhardness profiles of the experimental materials

were also suppressed compared with fusion welding process. Friction welding process is a well-known process due to low heat input and faster cooling process, which is helpful to cool down rapidly and also to form austenite phase in lesser time. Hence, all friction welds contained more amount of ferrite phase in weld zone than the base metal.

\subsection{Tensile Strength of the Weld Joints}

The purpose of the tensile test was to evaluate the strength of the welds and also to examine the influence of welding defects on the joint performance. The tensile tested values and corresponding experimental numbers are plotted in Fig. 7.

The transverse tensile strength, yield strength, and percentage of elongation of all joints were evaluated. The tensile test results are presented in Table 6. From Table 6, it is clear that the tensile strength of weld metal was higher than the base metal. From Fig. 8, it is clearly seen that the fracture occurred away from the joint zone. Fracture had occurred only in the base metal. The maximum tensile strengths (828 and $822 \mathrm{MPa}$ ) were obtained for higher upsetting pressure and higher friction pressure. From Table 6, it is clearly identified that Experiment Nos. 15 and 16 resulted in lower tensile strengthen joints (728 and $720 \mathrm{MPa})$.

This might be due to the increased heating and upsetting pressure. The fractured surface of tensile specimen was analyzed using SEM. The fracture surface of the tensile tested fractrograph is shown in Fig. 8. Fractured surface revealed elongated grains with varying dimples size. Hence it was confirmed that the mode of failure was ductile. Coarse dimple sizes were observed in higher upsetting pressure (Exp. No. 16) and higher heating pressure (Exp. No. 16).

\subsection{Charpy V-notch Impact Toughness of Welds}

The toughness of the friction welds was evaluated through impact testing. The Charpy V-notch impact tests were carried out from friction welded joints at various temperatures such as room temperature (RT), $-50,-100,-150$, and $-196{ }^{\circ} \mathrm{C}$. The impact tested values are presented in Table 7.

The toughness of base metal was $160 \mathrm{~J}$ which was lower than the toughness of friction welded joints. From Table 7, it is clear that the friction welded joints exhibited higher impact toughness than the base metal. Ibrahim et al. [26] tested the impact energy of duplex stainless steel by TIG and SMAW processes with different low temperatures, and found that the impact energies for SMAW process were $15,7,6$, and $5 \mathrm{~J}$ at $-50,-100,-150$, and $-196{ }^{\circ} \mathrm{C}$, respectively; for TIG process were $11,9,6$ and $4 \mathrm{~J}$ at $-50,-100,-150$ and $-196{ }^{\circ} \mathrm{C}$, respectively. The impact energy of friction welded joints was much higher than that of the fusion joints. From Table 7, the impact toughness values were observed to be reduced with the reduction in temperature from the room temperature to cryogenic temperature. The increment of the impact toughness was approximately $13.5 \%$ (RT), $13.54 \%$ $\left(-50{ }^{\circ} \mathrm{C}\right), 43.5 \%\left(-100{ }^{\circ} \mathrm{C}\right), 39.5 \%\left(-150{ }^{\circ} \mathrm{C}\right)$, and $23.2 \%$ $\left(-196{ }^{\circ} \mathrm{C}\right)$, when compared to the base metal. The average ferrite content $(51.8 \%)$ was almost same for all the impact tested samples after testing at $-196{ }^{\circ} \mathrm{C}$. This could be attributed the negligible amount of plastic deformation exerted at $-196{ }^{\circ} \mathrm{C}$ and accordingly no transformation of austenite to deformed martensite would take place. At $-196{ }^{\circ} \mathrm{C}$, the friction welds were metastable and underwent a partial transformation to martensite during deformation. Evidence of martensitic transformation had been detected in the crack tip plastic zone of austenitic and duplex stainless steels impact specimens at cryogenic temperatures as low as liquid nitrogen [27]. At cryogenic temperature, welds typically exhibited higher strength and lower toughness than their base metal. The inferior weld zone toughness was associated with high non metallic inclusion and delta ferrite content and higher strength level [28]. The ferrite was of a body centered cubic (bcc) structure, its yield strength was a function of temperature i.e., it increased as the temperature was lowered due to increased lattice friction stress and pinning of mobile dislocations with interstitial atoms (carbon and nitrogen). On the other side, the cleavage fracture stress of ferrite was not a function of temperature and was only varied by microstructural parameters such as grain size and dislocation density [29]. The typical fractured surface of the impact tested fractrograph for various temperatures is shown in Fig. 9. 


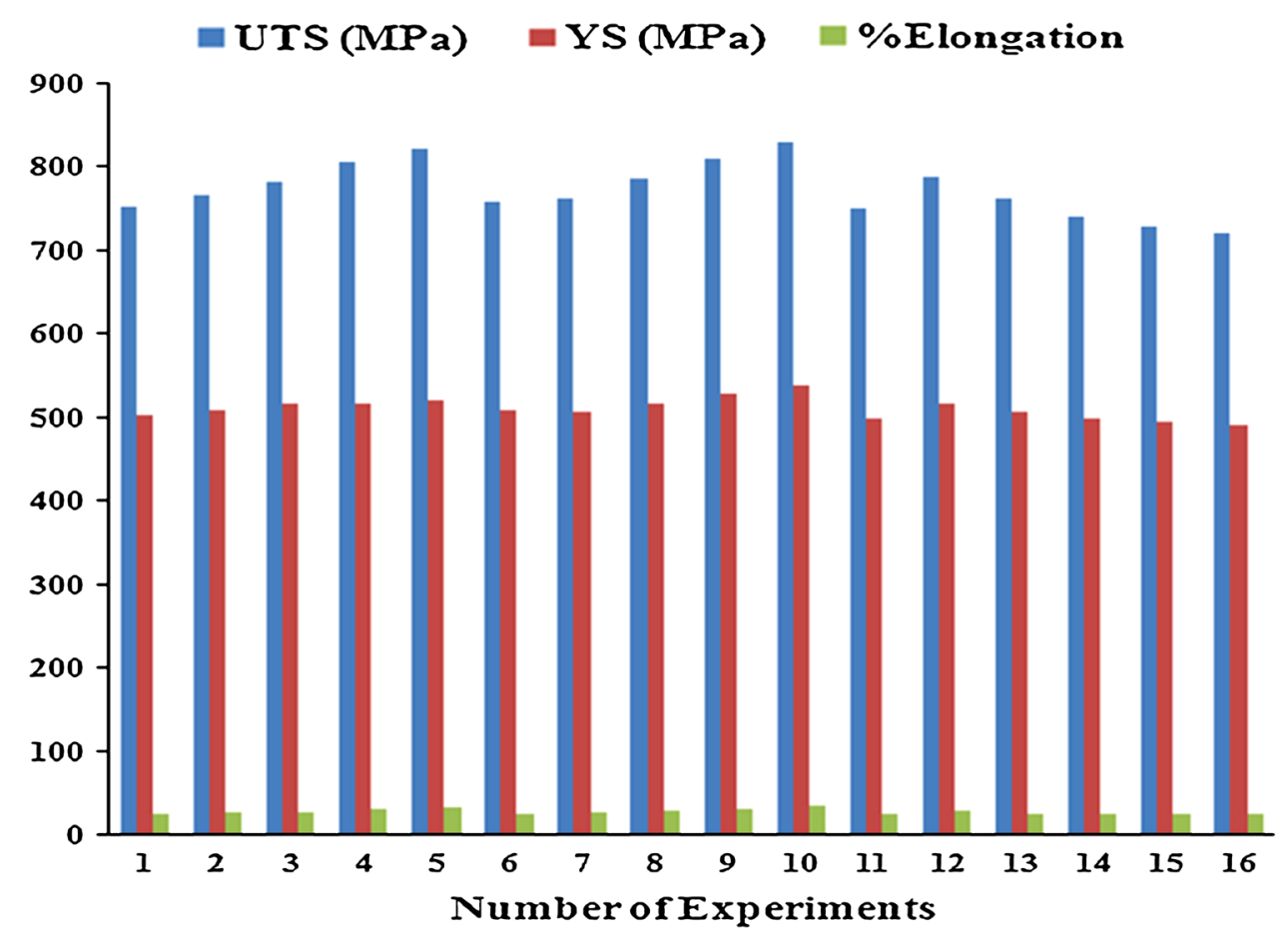

Fig. 7 Tensile test results of the experimental materials

Table 6 Experimental results of tensile test

\begin{tabular}{|c|c|c|c|c|c|c|c|c|c|}
\hline $\begin{array}{l}\text { Exp. } \\
\text { No. }\end{array}$ & $\begin{array}{l}\mathrm{HP} \\
(\mathrm{MPa})\end{array}$ & $\begin{array}{l}\text { UP } \\
(\mathrm{MPa})\end{array}$ & $\begin{array}{l}\mathrm{HT} \\
(\mathrm{s})\end{array}$ & $\begin{array}{l}\text { UT } \\
\text { (s) }\end{array}$ & $\begin{array}{l}\text { SoR } \\
(\mathrm{r} / \mathrm{min})\end{array}$ & $\begin{array}{l}\text { Ultimate tensile } \\
\text { strength (MPa) }\end{array}$ & $\begin{array}{l}\text { Yield strength } \\
\text { (MPa) }\end{array}$ & $\begin{array}{l}\text { Elongation } \\
(\%)\end{array}$ & $\begin{array}{l}\text { Fracture } \\
\text { location }\end{array}$ \\
\hline 1 & 70 & 145 & 6 & 3 & 1,500 & 752 & 502 & 26.3 & Base \\
\hline 2 & 70 & 155 & 7 & 4 & 2,000 & 766 & 508 & 27.2 & Base \\
\hline 3 & 70 & 165 & 8 & 5 & 2,500 & 781 & 517 & 28.4 & Base \\
\hline 4 & 70 & 175 & 9 & 6 & 3,000 & 805 & 516 & 31.1 & Base \\
\hline 5 & 80 & 145 & 7 & 5 & 3,000 & 822 & 520 & 34.1 & Base \\
\hline 6 & 80 & 155 & 6 & 6 & 2,500 & 758 & 508 & 26.7 & Base \\
\hline 7 & 80 & 165 & 9 & 3 & 2,000 & 762 & 507 & 26.8 & Base \\
\hline 8 & 80 & 175 & 8 & 4 & 1,500 & 785 & 516 & 29.2 & Base \\
\hline 9 & 90 & 145 & 8 & 6 & 2,000 & 809 & 528 & 31.2 & Base \\
\hline 10 & 90 & 155 & 9 & 5 & 1,500 & 828 & 538 & 34.8 & Base \\
\hline 11 & 90 & 165 & 6 & 4 & 3,000 & 750 & 499 & 26.0 & Base \\
\hline 12 & 90 & 175 & 7 & 3 & 2,500 & 788 & 516 & 29.8 & Base \\
\hline 13 & 100 & 145 & 9 & 4 & 2,500 & 761 & 507 & 26.7 & Base \\
\hline 14 & 100 & 155 & 8 & 3 & 3,000 & 740 & 498 & 26.2 & Base \\
\hline 15 & 100 & 165 & 7 & 6 & 1,500 & 728 & 494 & 25.3 & Base \\
\hline 16 & 100 & 175 & 6 & 5 & 2,000 & 720 & 490 & 24.8 & Base \\
\hline \multicolumn{6}{|c|}{ Base metal } & 620 & 450 & 25 & - \\
\hline
\end{tabular}

Kacar et al. [30] and Sieurin et al. [31] investigated the fracture toughness of a welded duplex stainless steel by submerged arc weldments (SAW) at subzero temperatures. At room temperature, the cleavage fracture had occurred and consequently, plastic deformation prevailed and ductile behavior was verified. As temperature decreased, and at a certain low temperature (cryo temperature), the yield strength of ferrite became higher and its cleavage fracture occurred. At this stage, a transition from ductile fracture through plastic deformation to brittle fracture by cleavage had taken place. 

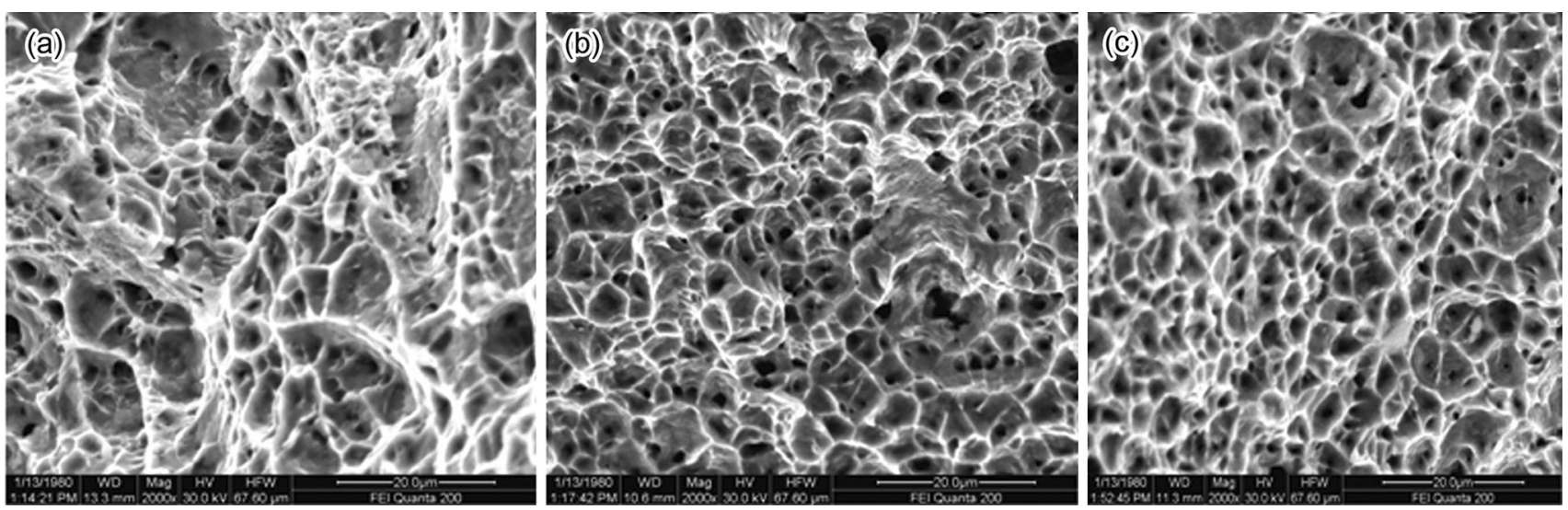

Fig. 8 SEM fracture surfaces of the tensile test: a Exp. No. 2, b Exp. No. 10, c Exp. No. 16

Table 7 Impact toughness of friction welds

\begin{tabular}{llllll}
\hline Exp. & \multicolumn{4}{l}{ Impact strength $(\mathrm{J})$} \\
\cline { 2 - 6 } & $\begin{array}{l}\text { Room } \\
\text { temperature }\end{array}$ & $-50{ }^{\circ} \mathrm{C}$ & $-100{ }^{\circ} \mathrm{C}$ & $-150{ }^{\circ} \mathrm{C}$ & $-196{ }^{\circ} \mathrm{C}$ \\
& 163 & 62 & 50 & 41 & 14 \\
1 & 176 & 68 & 53 & 42 & 15 \\
2 & 183 & 75 & 55 & 42 & 17 \\
3 & 192 & 86 & 57 & 43 & 19 \\
4 & 186 & 70 & 52 & 41 & 15 \\
5 & 193 & 75 & 54 & 44 & 16 \\
6 & 198 & 78 & 57 & 46 & 18 \\
7 & 202 & 87 & 51 & 41 & 21 \\
8 & 186 & 79 & 56 & 38 & 15 \\
9 & 192 & 84 & 57 & 41 & 20 \\
10 & 194 & 88 & 58 & 43 & 21 \\
11 & 197 & 90 & 60 & 45 & 24 \\
12 & 196 & 87 & 57 & 39 & 18 \\
13 & 202 & 90 & 58 & 41 & 22 \\
14 & 205 & 92 & 60 & 44 & 26 \\
15 & 208 & 95 & 62 & 47 & 30 \\
16 & 160 & 70 & 40 & 30 & 11 \\
Base & & & & & \\
metal & & & & & \\
\hline
\end{tabular}

\subsection{Corrosion Study of the Welds}

The corrosion tests were conducted at room temperature using Electrochemical Analyzer. The tests were conducted in a conventional three-electrode cell, with Pt foil as the auxiliary electrode, and a saturated calomel electrode (SCE) as the reference electrode. Polarization plots were obtained for all the weld samples after completing the corrosion testing. The value of the corrosion current for each sample was obtained by drawing tangent to the Tafel plots as shown in Fig. 10.

The corrosion behavior of welded sample was evaluated by the corrosion current. At a fixed temperature, the lower the corrosion current in polarization test the higher was the corrosion resistance [29]. The results of corrosion test are presented in Table 8. It shows that the high corrosion current led to high amount of corrosion rate in all the friction welds. In particular, the lower the friction and upset pressure, the higher was the rotational speed and the corrosion rate was much higher than the other set of parameters.

The corroded samples were further investigated by SEM analysis (Fig. 11). Microvoids and pits were seen in most of the weld samples due to $\mathrm{NaCl}$ solution. In weld material,
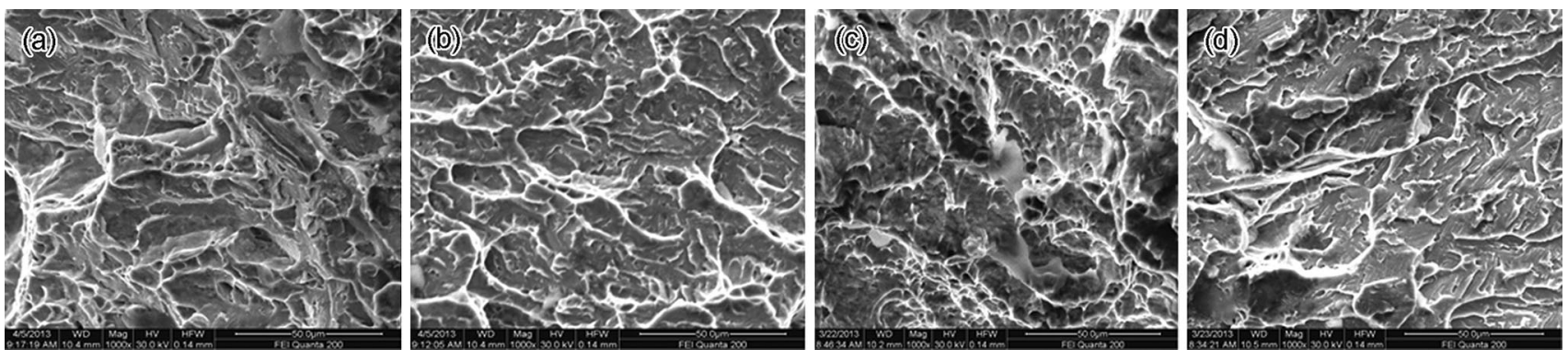

Fig. 9 Typical SEM fractured surfaces of the impact tested samples: a room temp. (Exp. No. 4), $\mathbf{b}-50{ }^{\circ} \mathrm{C}$ (Exp. No. 8 ), $\mathbf{c}-100{ }^{\circ} \mathrm{C}$ (Exp. No. 14), $\mathbf{d}-196{ }^{\circ} \mathrm{C}($ Exp. No. 16) 

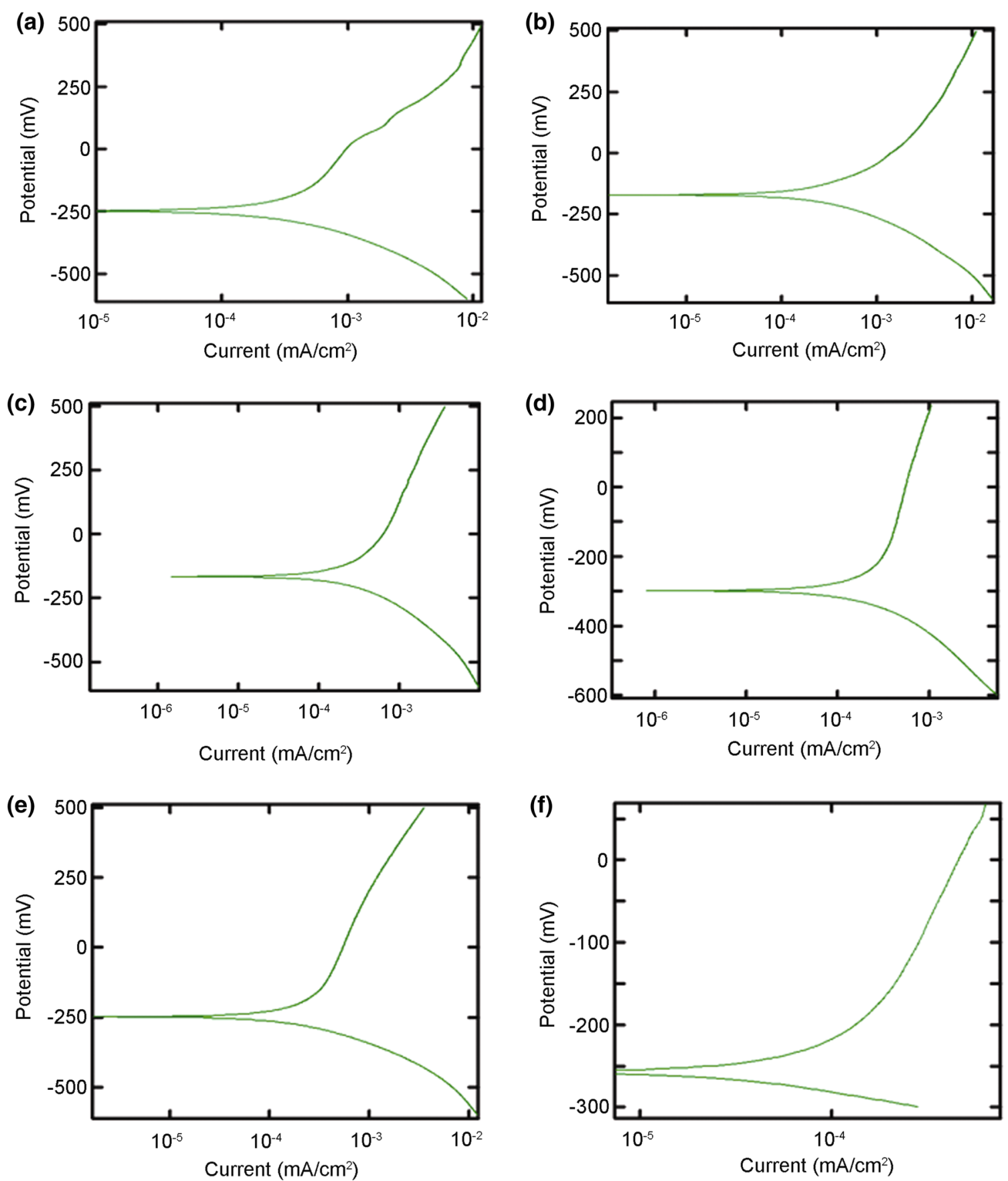

Fig. 10 Typical polarization plots of corrosion tested samples: a Exp. No. 1, b Exp. No. 4, c Exp. No. 7, d Exp. No. 10, e Exp. No. 12, f Exp. No. 15

cavitations appeared to form pits and a few micro voids along the ferrite-austenite boundaries. The formation of the oxide layer was less protective on the welds, as the current in the passive region was higher than that of the base material. However, the welding parameters influenced the dissolution in the passive range, which suggested that the microstructure, i.e., the distribution of the ferritic and austenitic phases played an important role for dissolution of the weld metal. The thin oxide layer formed on stainless steels had a high resistance and low capacitance behavior. The polarization resistance was related to the corrosion resistance, as a necessary charge transfer which can only occur through the oxide layer [32]. From Table 8 and Fig. 11, it is understood that the corrosion rates for all the 
Table 8 Experimental results of corrosion test

\begin{tabular}{lll}
\hline Exp. No. & $\begin{array}{l}\text { Corrosion current } \\
I_{\text {corr }} \times 10^{-5}\left(\mathrm{~mA} / \mathrm{cm}^{2}\right)\end{array}$ & $\begin{array}{l}\text { Corrosion rate } \\
(\mathrm{mm} / \mathrm{y})\end{array}$ \\
\hline 1 & 7.244 & 0.00078041 \\
2 & 7.439 & 0.0008015 \\
3 & 7.723 & 0.00089432 \\
4 & 7.982 & 0.00091212 \\
5 & 8.175 & 0.00092132 \\
6 & 6.891 & 0.00053412 \\
7 & 6.363 & 0.00049821 \\
8 & 5.849 & 0.00039436 \\
9 & 5.392 & 0.00039124 \\
10 & 4.267 & 0.00048132 \\
11 & 5.482 & 0.00039985 \\
12 & 4.327 & 0.00048235 \\
13 & 3.629 & 0.00041734 \\
14 & 2.683 & 0.00029832 \\
15 & 1.916 & 0.00021968 \\
16 & 4.482 & 0.00038426 \\
Base metal & 8.312 & 0.00093484 \\
\hline
\end{tabular}
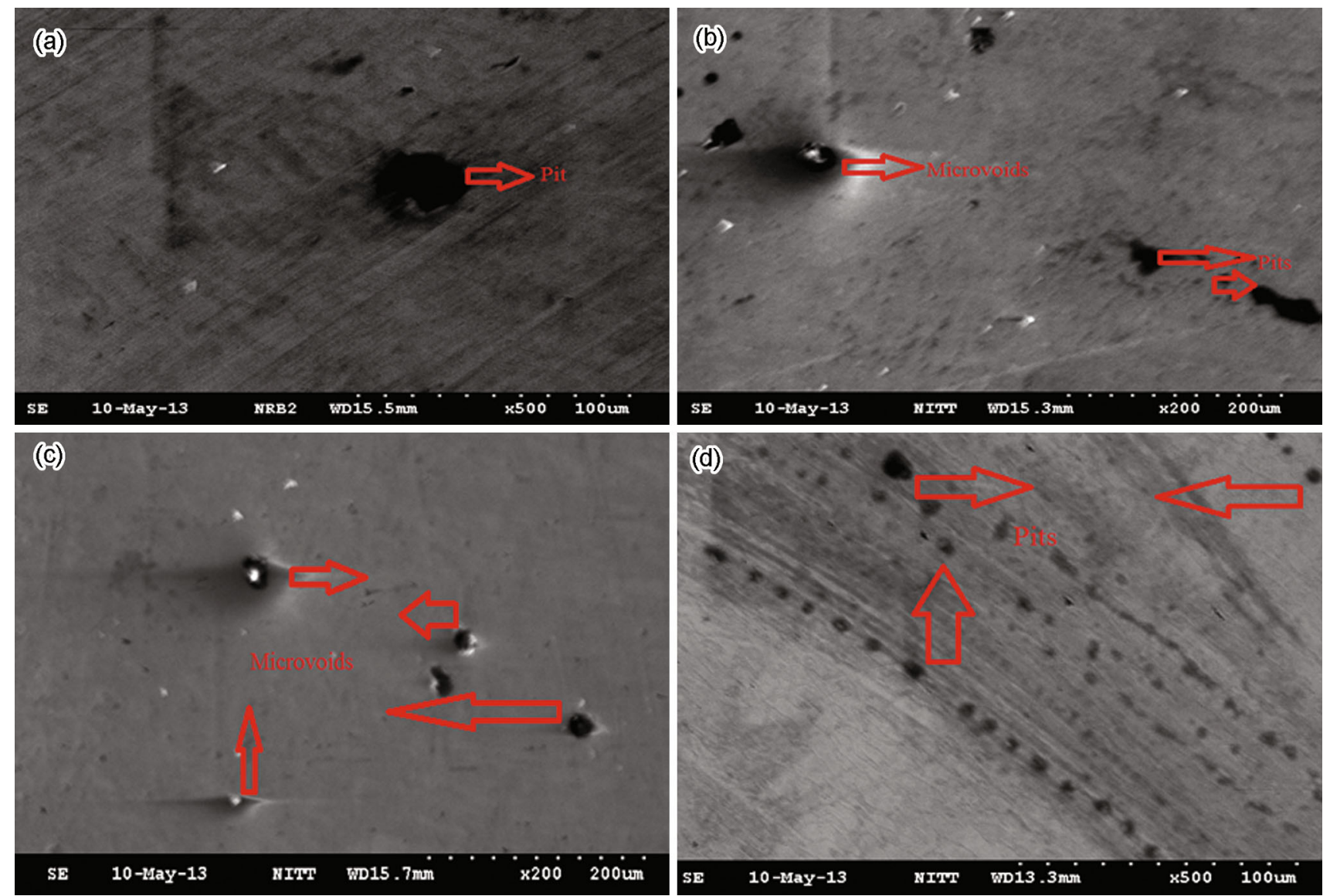

Fig. 11 SEM images of the corrosion tested samples: a Exp. No. 1, b Exp. No. 5, c Exp. No. 12, d Exp. No. 15 
and a higher tensile strength was achieved (828 MPa). From the above experimental values, it was concluded that friction pressure and upsetting pressure were the major parameters which dictated the weld strength.

(3) The weld microstructure had nearly equal volume of austenite and ferrite phases (average values of ferrite and austenite content in weld metal were $51.86-55.96 \%$ and $48.14-44.04 \%$, respectively).

(4) The higher tensile strength of the joints obtained from higher friction pressure (125 $\mathrm{MPa})$ and upset pressure (200 MPa) was within the selected range. The fractured surface revealed fine dimples and also confirmed the ductile mode of fracture.

(5) The friction welded duplex stainless steel joints exhibited higher impact energy than the arc welding of duplex stainless steel joints under room temperature and cryo condition.

(6) The impact fracture surface appeared like ductile fracture at room temperature, and at the cryo conditions, the fracture took place through plastic deformation to brittle fracture. The fracture surface appeared like cleavage mode.

(7) The corrosion resistance of friction welded samples was better than the fusion processed joints.

\section{References}

[1] J. Charles, Weld. World (UK) 36, 43 (1995)

[2] J.B. Vogt, Mater. Proc. Technol. 117, 364 (2001)

[3] A. Mateo, L. Llanes, N. Akdut, M. Anglada, Mater. Sci. Eng. A 319-321, 516 (2001)

[4] R.D. Kane, Adv. Mater. Proc. 144(1), 16 (1993)

[5] B. Josefson, J.O. Nilsson, A. Wilson, Proc. Conf. Duplex Stainl. Steel 91, 67 (1991)

[6] C. Petterson, S. Fager, Welding Practice for the Sandvik Duplex Stainless Steels SAF2304, SAF2205 and SAF2507 (AB Sandvik Steel, S-811 81 Sandviken, 1995), p. 81

[7] J.O. Nilsson, Mater. Sci. Techbol. 8, 685 (1992)
[8] T. Thorvaldsson, H. Eriksson, J. Kutka, A. Salwén, Influence of microstructure on mechanical properties of a duplex stainless steel. Stainless Steel '84, Göteborg, 1, 101 (1984)

[9] R.N. Gunn, Reduction in fracture toughness due to intermetallic precipitates in duplex stainless steels. Duplex America 2000, Houston (2000), pp. 299-314

[10] L. Karlsson, L. Bengtsson, U. Rolander, S. Pak, Applications of Stainless Steel '92, Stockholm, vol. 1 (1992), pp. 335-344

[11] S. Hertzman, B. Lehtinen, E. Symniotis-Barradal, Applications of Stainless Steel '92, Stockholm, vol. 1 (1992), pp. 345-359

[12] L. Karlsson, S. Rigdal, F. Lake, Effects of intermetallic phases in duplex stainless steel weldments. Duplex America 2000, Houston, (2000), pp. 257-272

[13] L. Karlsson, Duplex stainless steel weld metals-effects of secondary phases. Duplex Stainless Steels'97, Maastricht, vol. 1 (1997) pp. 43-58

[14] M. Liljas, The welding metallurgy of duplex stainless steels. Duplex Stainless Steels '94, Glasgow, 1994

[15] Y.S. Sato, T.W. Nelson, C.J. Sterling, R.K. Steel, C.O. Pettersson, Mater. Sci. Eng. A 397, 376 (2005)

[16] Z.M. Cvijović, D.V. Mihajlović, V.R. Knežević, Mater. Sci. Forum 282-283, 323 (1998)

[17] H. Mumin Sachin, E. Akata, J. Mater. Process. Technol. 142, 239 (2003)

[18] M. Sahin, J. Mater. Des. 28, 2244 (2007)

[19] Duplex Stainless Steel, Outokumpu. http://www.outokumpu. com/29153.epibrw

[20] J.C. Lippold, I. Varol, V.A. Baeslack III, in Duplex Stainless Steels'91, ed. by J. Charles, S. Bernhardsson (Les Editions de Physique, Les Ulis, 1991), p. 383

[21] J.C. Lippold, W. Lin, S. Brandi, I. Varol, W.A. Baeslack, in: Duplex Stainless Steels'94, Glasgow, 1994, ed. by T.G. Gooch, Paper 116

[22] E.I. Kivineva, N.E. Hannerz, in: Duplex Stainless Steels'94, Glasgow, 1994, ed. by T.G. Gooch, Paper 7

[23] P.A. Molian, J. Mater. Sci. Lett. 4, 281 (1985)

[24] S. Heino, E.M. Knutson-Wedel, B. Karlsson, J. Mater. Sci. Technol. 15(1), 101 (1999)

[25] N. Suutala, Metall. Mater. Trans. A 14, 191 (1983)

[26] O.H. Ibrahim, I.S. Ibrahim, T.A.F. Khalifa, Eng. Fail. Anal. 17, 1069 (2010)

[27] W.J. Mills, Int. Met. Rev. 42 (1997)

[28] J.W. Chan, Adv. Cryog. Eng. 55, 38 (1992)

[29] G. Han, S. Fukuyama, K. Yokogawa, Mater. Sci. Technol. 15, 909 (1999)

[30] R. Kacar, M. Acarer, Mater. Sci. Eng. A 363, 290 (2003)

[31] H. Sieurin, R. Sandstom, Eng. Fract. Mech. 73, 377 (2006)

[32] Z. Sun, M. Kuo, I. Annergren, D. Pan, Mater. Sci. Eng. A 356, 274 (2003) 